\title{
Psychology of Music
}

Perceived performance anxiety in advanced musicians specializing in different musical genres

loulia Papageorgi, Andrea Creech and Graham Welch

Psychology of Music 2013 41: 18 originally published online 4 July 2011

DOI: $10.1177 / 0305735611408995$

The online version of this article can be found at:

http://pom.sagepub.com/content/41/1/18

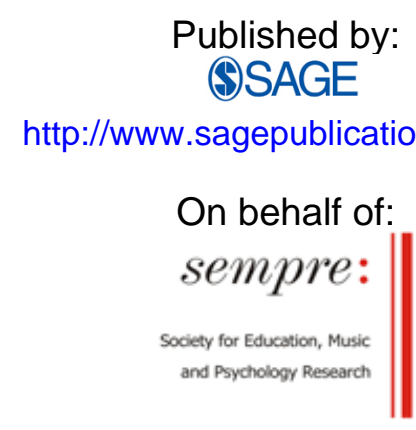

Society for Education, Music and Psychology Research

Additional services and information for Psychology of Music can be found at:

Email Alerts: http://pom.sagepub.com/cgi/alerts

Subscriptions: http://pom.sagepub.com/subscriptions

Reprints: http://www.sagepub.com/journalsReprints.nav

Permissions: http://www.sagepub.com/journalsPermissions.nav

>> Version of Record - Dec 30, 2012

OnlineFirst Version of Record - Jul 5, 2011

OnlineFirst Version of Record - Jul 4, 2011

What is This? 


\title{
Perceived performance anxiety in advanced musicians specializing in different musical genres
}

Psychology of Music 41(1) 18-41

(C) The Author(s) 2011

Reprints and permissions: sagepub. co.uk/journalsPermissions.nav DOI: $10.1177 / 0305735611408995$ pom.sagepub.com

@SAGE

\author{
Ioulia Papageorgi, Andrea Creech, and \\ Graham Welch \\ University of London, UK
}

\begin{abstract}
Most research on musical performance anxiety has focused on musicians coming from a classical background, and performance anxiety experiences of musicians outside the western classical genre remain under-researched. The aim of this study was to investigate perceived performance anxiety experiences in undergraduate and professional musicians and to explore whether musical genre specialization (Western classical, jazz, popular, Scottish traditional) affected musicians' performance anxiety experiences. The study addressed questions exploring the perceived intensity of performance anxiety, the perceived contributing factors, changes in perceived anxiety levels as performances approached (one hour before, immediately before and during performance) and the perceived impact of performance on the quality of performance. Participants were 244 musicians, 170 undergraduates and 74 portfolio career musicians. Data were collected through a questionnaire survey. Findings suggested that performance anxiety was of concern for a significant majority of undergraduate and professional musicians. Musicians from all participating musical genres shared similar perceptions and concerns. Anxiety appeared to have negative connotations, although it was also reported as beneficial. Solo performance generated more anxiety compared to group performance. Overall, the impact of anxiety on performance was related to its perceived severity during performance, and was mediated by musicians' performance experience and their general susceptibility to anxiety. The musical genre in which participants specialized affected their perceived anxiety levels. Western classical musicians were generally found to report higher levels of performance anxiety. This study has provided indications that musicians specializing in different musical genres may experience performance anxiety in quantitatively and qualitatively different ways. Further research would benefit from investigating factors contributing to these variations.
\end{abstract}

\section{Keywords}

advanced performance, group performance, musical genre, performance anxiety, solo performance

\section{Corresponding author:}

Ioulia Papageorgi, Institute of Education, University of London, 20 Bedford Way, London WC1 OAL, UK.

[email: i.papageorgi@ioe.ac.uk] 
Musical performance is a highly effortful activity. In order to develop and sustain expertise in performance musicians need to be physically, emotionally and mentally fit (Papageorgi \& Kopiez, in press). The quality of performance at any given point is affected by the performer's level of expertise and adequacy of preparation, but can be affected by psychological factors such as self-perceptions, self-efficacy beliefs and the experience of performance anxiety.

Performance anxiety has been described as 'a state of arousal and anxiety occurring before or while a person is performing non-anonymously in front of an audience producing a valuable or evaluated task touching on his/her self-esteem' (Kesselring, 2006, p. 309). The level of anxiety experienced by a person can fluctuate between performances, and individual musicians encounter anxiety to different extents (Steptoe, 2001). It can be a very intense experience, and one of the "few activities in life which can produce tension and anxiety as rapidly and thoroughly as playing a musical instrument in public' (Havas, 1995, p. 13).

A review of relevant research suggests that musical performance anxiety is a critical problem for $15 \%$ to $25 \%$ of professional musicians (Steptoe, 2001). Studies looking at professional and higher education student musicians have indicated that performance anxiety is one of the most frequently reported problems (Williamon \& Thompson, 2006), and that it can negatively affect the quality of performance (Dews \& Williams, 1989; Fishbein, Middlestadt, Ottati, Strauss, \& Ellis, 1988; Gustafson \& Rawson, 1983; Marchant-Haycox \& Wilson, 1992; Schulz, 1981; Wesner, Noyes, \& Davis, 1990). Female musicians in particular appear to be more sensitive to performance anxiety (Dews \& Williams, 1989; Fishbein et al., 1988; Kenny \& Osborne, 2006; Papageorgi, 2006, 2007; Rae \& McCambridge, 2004; Ryan, 2004; Wesner et al., 1990).

Performance anxiety in music is a complex construct, which has close links with other forms of anxiety such as social anxiety and test anxiety. Performance usually takes place in front of an audience, often involves musicians playing together, and therefore has a social component. Social phobia literature has often defined musical performance anxiety as a specific type of performance-related social phobia (Barlow, 1988; Clark \& Agras, 1991; Turner \& Biedel, 1989), although there is a distinction between these concepts (Rapee \& Heimberg, 1997). Research has found a connection between performance anxiety and social phobia (Cox \& Kenardy, 1993; Osborne \& Franklin, 2002; Steptoe \& Fidler, 1987). Osborne and Franklin (2002) found partial support for conceiving of musical performance anxiety as a social phobia, as their sample showed some of the cognitive distortions of social phobia. Cox and Kenardy (1993) found that $50 \%$ of the musicians in their sample were socially phobic. Social phobia also appeared to be the major determinant of the presence and manifested level of anxiety within a solo performance setting. Debilitating performance anxiety has also been associated with factors similar to those evidenced in social phobia, such as lack of control, the reactions of important others, fear of negative evaluation, judgmental attitudes (Lehrer, 1987), social situations, fear of crowds and catastrophizing (Steptoe \& Fidler, 1987). Musical performance has many similarities with an academic examination, particularly with respect to the evaluative element, potential fear of negative feedback, worry about possible failure and potential loss of status or self-esteem when failure is experienced. Although musical performance anxiety shares common features with the concept of test anxiety, it is a more complicated construct because performance is evaluated in real time.

One of the major concerns for musicians is the impact of anxiety on the quality of performance. A number of theories explaining the relationship between anxiety and performance efficiency have been formulated, which may be useful in understanding their relationship within a music performance context. These include: 
- The Yerkes-Dodson law (1908), which is one of the earliest experimentally based statements concerning the relationship between drive and learning (Levitt, 1968). The YerkesDodson law supports an inverted U relationship between physiological arousal and performance efficiency. It supports that very low or very high arousal levels do not enhance performance quality, and that optimal performance quality is evidenced at medium levels of arousal. Deterioration occurs more rapidly if the task to be performed is complex or not prepared sufficiently (Wilson, 2002). Steptoe (1983) has reported evidence to support the inverted-U pattern in terms of tension and musical performance for students and professional musicians. Wilson (1973, 1997 and 2002), elaborated and extended the Yerkes-Dodson relationship, and developed a three-dimensional model of arousal and performance efficiency. Wilson's model suggests that arousal and anxiety levels depend upon the interaction between the trait anxiety of the performer, task difficulty and the prevailing degree of situational stress.

- Lang, Miller, \& Levin's (1988) three-factor model of anxiety states that anxiety arises from the interaction between three major components: cognitive (thoughts related to mental images of danger and threat), behavioural (inclination to keep or run away from everything perceived as dangerous) and physiological (bodily reactions to heightened arousal). Within this framework, anxiety symptoms are conceptualized as falling into the three aforementioned categories (Lang et al., 1988).

- The multidimensional theory of anxiety was developed to explain competitive anxiety in sport (Martens, Burton, Vealey, Bump, L., \& Smith, 1990). The theory distinguishes between two types of anxiety, cognitive anxiety and somatic anxiety, which are theorized to interact with one another in different ways. The theory hypothesizes that (1) there will be a negative but linear relationship between cognitive anxiety and performance; (2) there will be an inverted U relationship between somatic anxiety and performance; and (3) somatic anxiety should decline once performance begins but cognitive anxiety may remain high if confidence is low. Miller and Chesky (2004) tested the applicability of the multidimensional anxiety theory to musicians, and found support for the existence of the two distinct, yet related dimensions of performance anxiety (cognitive and somatic anxiety), which may interact with levels of self-confidence.

Theories explaining performance anxiety within a music performance context are in line with the multidimensional theory of anxiety and have conceptualized it as a multidimensional construct operating over time (Hallam, 1998; LeBlanc, 1994; Papageorgi, Hallam, \& Welch, 2007). LeBlanc's (1994) theory of sources of variation in levels of musical performance anxiety identified some of the key variables that may affect anxiety levels and was a precursor to more recent models focusing on the performer through the various stages of performance preparation, enactment and follow up (Papageorgi et al., 2007). Musical performance anxiety has been represented as a multi-dimensional construct within a transactional model. It has been suggested that the level of arousal depends upon the interaction of the following: (a) the performer's susceptibility to experiencing anxiety when the commitment to perform is made (which may include individual characteristics such as gender, age, trait anxiety, self-esteem, self-concept and self-efficacy; (b) the performer's task efficacy (which relates to the process of preparation, learning approach, motivation to learn, task difficulty and value, and anxiety coping strategies; and (c) the characteristics of the specific environment where the individual is expected to perform (which can be influenced by parameters such as audience presence, perceived degree of exposure and venue characteristics). 
Musical performance anxiety has been described as leading to the impairment of performance skills in a public context, to a degree unwarranted given the individual's musical aptitude, training, and level of preparation (Salmon, 1990, p. 3). However, some studies (e.g., Hamann, 1982; Spencer, 1969) found that anxiety can have motivational properties for more experienced musicians, as their performance can improve under conditions of increased anxiety. It appears that when anxiety is kept under control, the accompanying physiological arousal can serve as preparation for action and have a positive effect by increasing alertness and concentration. There is therefore a need to differentiate between maladaptive (or debilitating) and adaptive (or facilitating) forms of musical performance anxiety. What determines whether pre-performance arousal is beneficial or detrimental for musicians has not yet been clarified and research would benefit from empirical studies exploring factors that potentially influence the experience of adaptive and maladaptive forms of anxiety.

The majority of existing studies investigating performance anxiety have utilized quantitative methodologies by conducting experiments or social psychometric testing. In one of the earliest studies, Steptoe and Fidler (1987) investigated the incidence and correlates of performance anxiety (stage fright) in orchestral musicians from a cognitive social perspective using self-report attitude scales. More recent studies employing psychometric testing to measure the incidence, severity and correlates of performance anxiety through the use of self-report measures include Ryan and Andrews (2009), Kenny, Davis, and Oates (2004), Osborne and Kenny (2008) and Rae and McCambridge (2004). Experimental methodology has been used extensively (e.g., Jackson \& Latane, 1981; LeBlanc, Jin, Obert, \& Siivola, 1997; Yoshie, Kudo, Murakoshi, \& Ohtsuki, 2009). In a recent study, Yoshie et al. (2009) investigated the effects of social-evaluative performance conditions on subjective, autonomic and electromyographic reactions in 18 highly skilled pianists. Findings suggested that under competitive conditions the performance quality was impaired compared to the rehearsal condition. Musicians reported significantly higher performance anxiety and evidenced increased physiological and electromyographic activity that can disrupt fine motor control.

Most of the research reviewed has been conducted with Western classical musicians. The limited research with other-than-classical musicians suggests that popular musicians consider performance anxiety to be one of the major sources of stress and evidence high levels of neuroticism and psychoticism (Wills \& Cooper, 1988; Cooper \& Wills, 1989). Nevertheless, the performance anxiety experiences of musicians outside the western classical genre remain under-researched and we are not yet in a position to say whether they share similar or different experiences to their classical counterparts. Bearing in mind the differences between classical and other-than-classical performance contexts and the fact that the latter 'tend to go about acquiring their skills and knowledge in ways that are quite distinct from the traditional methods of formal music education' (Welch et al., 2004, p. 256), it may be hypothesized that musicians of different musical genres may conceptualize and respond to musical performance anxiety differently.

The aim of this study was to fill in this gap in the literature by investigating the perceived experience of performance anxiety in a sample of undergraduate and professional musicians from four different musical genres (Western classical, jazz, popular, Scottish traditional) as expressed in a self-report questionnaire survey.

The specific research questions addressed were as follows:

1. How do musicians from different musical genres perceive the experience of anxiety in performance?

2. What factors do musicians from different musical genres perceive as contributing to performance anxiety? 
3. Does the perceived level of performance anxiety change as a performance approaches?

4. How do musicians perceive the impact of anxiety on the quality of performance?

5. What factors affect the perceived impact of performance anxiety on the quality of performance?

\section{Methodology and participants}

\section{Methodology}

Survey instrument. This study focused on how musicians perceive the experience of performance anxiety and therefore a self-report questionnaire was used. An innovative, web-based, Portable Document Format (PDF) ${ }^{1}$ survey instrument was designed, which allowed data from participants at remote sites to be sent automatically to a central server for collation. The 623-field online survey instrument was piloted and refined accordingly in preparation for the main data collection. The contents of the questionnaire survey included 57 questions and scales embracing a wide range of perspectives on musical performance that built on diverse literature sources, and included the following:

1. musical biographies (e.g.,variables related to the effects of age, sex, musical genre, instrumental type, experience);

2. psychological and social-psychological issues related to performance (e.g., performance anxiety, self-esteem, self-efficacy, musical identity, and the development of expertise), including an application of aspects of expertise theory and self-theories;

3. attitudes to learning (e.g., practice behaviours, views on teaching - ideal versus personal experience) and the social and environmental contexts for learning.

The current paper focuses on musicians' perceived levels of performance anxiety and the perceived effects of anxiety on the quality of performance. We were also interested in investigating the contribution of certain psychological characteristics that have been previously linked with performance anxiety on musicians' perceived performance anxiety and its perceived effects on the quality of performance. These were musical self-efficacy, self-esteem and trait anxiety. Data from the following survey scales and questions were used:

Psychological characteristics. Three published standardized scales measuring the following:

1. musical self-efficacy (Hargreaves et al., 2003 - based on Bandura, 1997; Sherer et al., 1982); two existing versions of this scale were used, one focusing on performance preparation and the second focusing on actual performance;

2. general self-esteem (Rosenberg, 1989);

3. general life anxiety (Spielberger, 1983).

Perceived levels of performance anxiety. Two short scales investigating perceived experience of performance anxiety, which required participants to rate the extent to which they experienced distress due to performance anxiety at three different points in time ( 1 hour, immediately before and during performance), when performing (1) solo and (2) as part of a group. Responses were measured on a seven-point Likert-type scale from 'no distress at all' to 'extreme distress' and a composite performance anxiety score for each type of performance (solo and group) was calculated by adding the responses of the scale items. 
Perceived effect of anxiety on performance quality. Two questions (items) investigating the perceived effects of performance anxiety on the quality of performance, which required participants to rate the extent to which their performances suffered or improved due to performance anxiety, when performing (1) solo and (2) as part of a group. Responses were measured on a seven-point Likert-type scale from 'significantly impaired' to 'significantly improved' and a composite score for each type of performance (solo and group) was calculated by adding the responses of the scale items.

Responses were analysed in SPSS. Measures of reliability after the data collection revealed highly satisfactory Cronbach $\alpha$ values that confirmed the high internal consistency of the measures used (see Table 1). Table 2 shows descriptive statistics on the scales used.

\section{Data collection and participants}

The data collection followed the British Psychological Society ethical guidelines. Second-year undergraduate musicians studying at one of three focus Higher Education Institution (HEIs) (which collaborated in the research project under the coordination of a fourth institution) and professional musicians known to the research team through professional networks (e.g., orchestras, music organizations) were approached. After being informed about the purpose of the study, those agreeing to take part were asked to sign a consent form. The survey asked participants to include their name so that they could be tracked down for a follow-up survey and an interview, and they were reassured that all answers were confidential and that any information provided would only be used for the purposes of the study. It was also made clear that participation was voluntary and that they had the right to withdraw from the study at any time. The contact details of the research team were included on the survey in case participants wanted to get in touch with questions about the study or to enquire about the findings.

Table I. Internal consistency measures for scales used

\begin{tabular}{ll}
\hline Scale & Cronbach $\alpha$ value \\
\hline Performance preparation self-efficacy & .792 \\
Musical performance self-efficacy & .851 \\
General self-esteem & .889 \\
General life (trait) anxiety & .924 \\
Experience of anxiety in solo performance & .728 \\
Experience of anxiety in group performance & .815 \\
\hline
\end{tabular}

Table 2. Descriptive statistics for scales used

\begin{tabular}{lllrr}
\hline Scale & $\begin{array}{l}\text { Minimum } \\
\text { value }\end{array}$ & $\begin{array}{l}\text { Maximum } \\
\text { value }\end{array}$ & Mean & \multicolumn{1}{c}{$S D$} \\
\hline Performance preparation self-efficacy & 40.00 & 77.00 & 63.76 & 10.86 \\
Musical performance self-efficacy & 31.00 & 77.00 & 60.47 & 10.92 \\
General self-esteem & 25.00 & 50.00 & 35.71 & 5.01 \\
General life (trait) anxiety & 28.00 & 80.00 & 56.95 & 9.95 \\
Experience of anxiety in solo performance & 3.00 & 21.00 & 11.99 & 3.85 \\
Experience of anxiety in group performance & 3.00 & 21.00 & 8.61 & 3.94 \\
\hline
\end{tabular}


Undergraduate musicians completed the questionnaire online in a university computer room in the presence of a researcher, using a web link given to them by the researcher. Professional musicians either completed the questionnaire online using a web link (which was specific to them and could only be used once) or completed a hard copy of the survey if that was more convenient to them.

Respondents to the survey were 244 musicians. This sample included undergraduate students studying for a Bachelor degree in music in UK Higher Education Institutions (70\%) and portfolio career musicians, self-reported as following an active performing and teaching career in the UK (30\%). Fifty-five percent were male and 45\% were female. Musicians were asked to report what they considered their main performance group (defined as the population of musicians who play within their genre, e.g., classical, jazz, traditional Scottish), and on this basis were classified into a musical genre group. For undergraduate musicians, this information was also cross-referenced with the degree they were pursuing at the time of the survey. Two of the institutions were conservatoires. The first is known for its jazz and popular music degrees, although it does also offer classical studies. The second conservatoire focuses on Scottish traditional and classical music studies. The third institution was a university, where music students mostly focus on classical music, although a smaller number of students focus on jazz performance.

Almost half of the respondents were classical musicians (48\%), whilst the rest of the sample comprised popular (27\%), jazz (18.4\%) and Scottish Traditional musicians (6.6\%). Table 3 summarizes the demographic information on participants.

The mean age of classical musicians was $29.1(S D=11.5)$, of popular musicians $21.2(S D=$ 4.46), of jazz musicians $23.8(S D=7.94)$ and of Scottish Traditional musicians $26.8(S D=$ 11.69). The overall mean age was $25.75(S D=9.94)$. Undergraduate musicians' age ranged from 18 to 49 years $($ mean $=21.5, S D=4.97)$ and portfolio musicians' age ranged from 23 to 62 years $($ mean $=35.9, S D=11.42)$.

The inter-relationship between participant gender and genre was found to be significantly uneven $\left(\chi^{2}(3)=14.18, p=.003\right)$. For example, whilst participant females constituted a majority of classical musicians (57\%), they were minorities in popular music (36\%), Scottish traditional $(38 \%)$ and jazz (29\%). These proportions reflected common genre $\times$ gender annual recruitment biases reported for each participant Higher Education Institution (HEI) in the previous three years.

Musicians were also asked to indicate their first study instrument. A wide range of instruments were reported, reflecting the main instrumental groups of each performance genre.

Table 3. Summary of demographic information on participants

\begin{tabular}{|c|c|c|}
\hline Musical genre & Professional status & Gender \\
\hline \multirow[t]{2}{*}{ Western classical (48\%) } & Undergraduate (47\%) & Male (43\%) \\
\hline & Professional $(53 \%)$ & Female $(57 \%)$ \\
\hline \multirow[t]{2}{*}{ Popular $(27 \%)$} & Undergraduate (95.5\%) & Male $(64 \%)$ \\
\hline & Professional $(4.5 \%)$ & Female $(36 \%)$ \\
\hline \multirow[t]{2}{*}{ Jazz (18.4\%) } & Undergraduate (91\%) & Male $(71 \%)$ \\
\hline & Professional $(9 \%)$ & Female $(29 \%)$ \\
\hline \multirow[t]{2}{*}{ Scottish Traditional (6.6\%) } & Undergraduate (69\%) & Male $(62 \%)$ \\
\hline & Professional (31\%) & Female $(38 \%)$ \\
\hline \multirow[t]{2}{*}{ Total } & Undergraduate (70\%) & Male $(55 \%)$ \\
\hline & Professional (30\%) & Female $(45 \%)$ \\
\hline
\end{tabular}


Most classical musicians played strings (violin, viola, cello), woodwind (oboe, flute, piccolo, recorder), brass (trumpet, trombone, tube), percussion, piano and voice. Popular musicians played bass guitar, electric guitar, percussion, keyboards, saxophone, trumpet and voice. Scottish traditional musicians played bagpipes, accordion, snare drum, clarsach and fiddle. Jazz musicians played saxophone, bass guitar, percussion, piano, trumpet and voice.

\section{Data analyses and findings}

\section{The perceived experience of anxiety in solo and group performances}

Participants were asked to rate the extent to which they felt distress due to performance anxiety one hour, immediately before and during solo and group performances on a seven-point Likerttype scale (from no distress at all to extreme distress). A paired-samples t-test on the composite performance anxiety score for each type of performance, indicated that there was a statistically significant difference in perceived performance anxiety level for solo and group performances $[t(233)=14.18, p<.0001]$. Solo performances tended to evoke higher levels of distress $(M=$ $12.00, S D=3.87)$ compared to group performances $(M=8.63, S D=3.94)$.

To investigate the influence of individual differences on participants' self-reported performance anxiety level, a multivariate analysis of variance was conducted with 'total perceived solo performance anxiety level' and 'total perceived group performance anxiety level' as the dependent variables. Gender (male/female), musical genre (classical, popular, jazz, Scottish traditional) and professional experience (undergraduate/professional musician) were the independent variables. Results indicated a significant small main effect of gender $[F(1,217)=8.36, p=.004$, partial $\left.\eta^{2}=.037\right]$ for solo performance anxiety level, indicating that female participants were more anxious compared to males (males $M=11.57, S D=3.99$; females $M=12.57, S D=3.67$ ). There was also a significant moderate main effect of gender $\left[F(1,217)=16.82, p<.0001\right.$, partial $\eta^{2}=$ .072] for group performance anxiety level, indicating again that female participants were more anxious compared to males (males $M=7.82, S D=3.65$; females $M=9.65, S D=4.03$ ).

A small significant interaction effect was observed between gender $\times$ professional experience $\left[F(1,217)=5.35, p=.02\right.$, partial $\left.\eta^{2}=.024\right]$ for solo performance anxiety level. Follow-up analyses indicated that the effect of gender was stronger for portfolio musicians (male portfolio $M=10.45, S D=3.33$; female portfolio $M=12.33, S D=3.83 ; p=.04$ ), with female musicians appearing to experience more distress in solo performance. The effect of gender was not statistically significant in the undergraduate cohort $(p>.05)$.

Finally, a small significant interaction effect was also found for gender $\times$ musical genre $\times$ professional experience for solo performance anxiety $\left[F(3,217)=2.72, p=.04\right.$, partial $\eta^{2}=$ $.036]$ and group performance anxiety $\left[F(3,217)=2.88, p=.03\right.$, partial $\eta^{2}=.038$. Figure 1 illustrates that both the strength and the direction of the effect of gender on undergraduate and portfolio musicians differed with respect to musical genre, for both perceived solo (left) and group (right) performance anxiety.

\section{Variables predicting perceived anxiety level}

To collectively investigate variables that could predict musicians' experience of distress due to performance anxiety, two hierarchical multiple linear regressions were conducted, each consisting of three Blocks. The dependent variable on the first regression was 'total solo performance anxiety level' and on the second 'total group performance anxiety level' (note that 

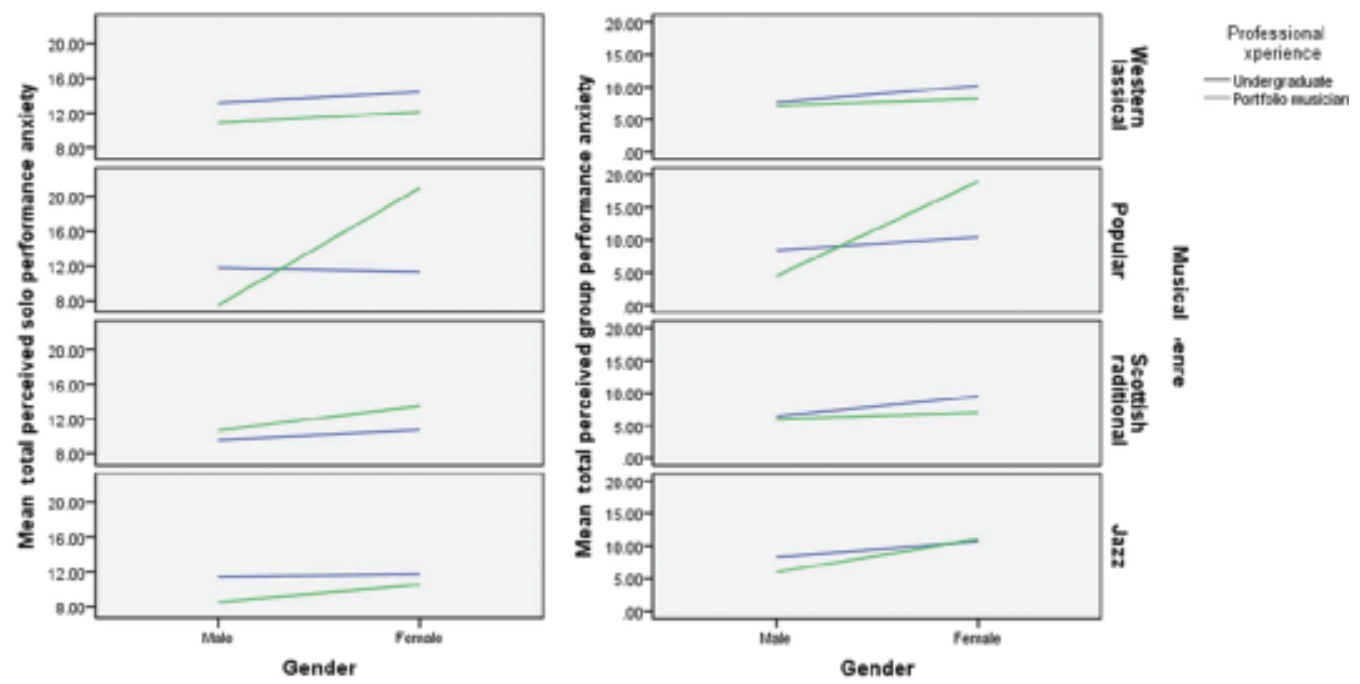

Figure I. Interaction effects on perceived anxiety levels (gender $\times$ professional experience $\times$ musical genre) in solo and group performances

higher values indicated higher levels of anxiety). For the first analysis, in Block 1, potential confounding variables were included (gender, age, professional status) to assess their potential impact. In Block 2, variables related to individual and personality differences were included (experience in performance, total perceived performance anxiety, perceived impact of performance anxiety on performance, total general self-esteem, total general life anxiety, total specific performance preparation efficacy, total specific performance efficacy). In Block 3, musical genre was added to see if it added anything more than the preceding variables in the regression model. This four category variable (four musical genres) was recoded into three dummy variables with 'classical musician' as the reference category. Each dummy variable showed the effect of being a popular, jazz and Scottish traditional musician as opposed to classical. The same rationale for selecting predictors was repeated for the second hierarchical regression. . $^{2,3,4}$

Predictors of perceived solo performance anxiety level. The first regression model, which consisted of potential confounding variables (age, gender, professional status), was not statistically significant $\left(R^{2}=.003 ; p>.05\right)$, indicating that they did not affect perceived levels of anxiety in solo performance. The second and third regression models were both statistically significant. The addition of Block 2 variables in model 2 resulted in a significant increase in $R^{2}\left(R^{2}\right.$ increase $=$ $.438, p(F$ change $)<.0001)$. There was also a small but significant increase in $\mathrm{R}^{2}$ after adding Block 3 musical genre variables in model $3\left(R^{2}\right.$ increase $=.04, p(F$ change $\left.)=.049\right)$. This final regression model (which consisted of all three stages in the hierarchy) $[F(12,100)=7.94, p<$ .0001 ) had an effect size, as calculated by the multiple $R$, of $.71, R^{2}=.51$ and adjusted $R^{2}=.44$, indicating that this model explained $44 \%$ of the variance in perceived solo performance anxiety. Table 4 summarizes the individual contributions of the predictor variables.

Overall, four variables made a statistically significant contribution to the third and final regression model. These were 'total perceived group performance anxiety' (semi-partial $r=.39$ ), 'perceived impact of performance anxiety on solo performance' (semi-partial $r=-.18$ ), 'jazz musician' (semi-partial $r=-.18$ ) and 'popular musician' (semi-partial $r=-.15$ ). The semi-partial 
Table 4. Contribution of variables in hierarchical regression on perceived solo performance anxiety (Block 3)

\begin{tabular}{lcrcl}
\hline Predictors & $\begin{array}{l}\text { Standardized } \\
\text { beta coefficient }\end{array}$ & $t$ & Sig. & $\begin{array}{l}\text { Semi-partial } \\
\text { correlation coefficient }\end{array}$ \\
\hline Female & .029 & -.375 & .709 & -.026 \\
Age & -.121 & -1.249 & .215 & -.088 \\
Portfolio musician & -.003 & -.030 & .976 & -.002 \\
Experience in solo performance & -.109 & -1.293 & .199 & -.091 \\
Total perceived group performance & .461 & 5.574 & $<.0001$ & .391 \\
anxiety & & & & \\
Perceived impact of performance & -.223 & -2.606 & .011 & -.183 \\
anxiety on solo performance & & & & \\
Total general self-esteem & -.045 & -.365 & .716 & -.026 \\
Total general life anxiety & -.145 & -1.159 & .249 & -.081 \\
Total specific performance & .188 & 1.674 & .097 & .117 \\
preparation efficacy & & & & -.081 \\
Total specific performance efficacy & -.160 & -1.157 & .250 & -.153 \\
$\begin{array}{l}\text { Popular musician } \\
\text { Scottish musician }\end{array}$ & -.194 & -2.186 & .031 & -.054 \\
Jazz musician & -.058 & -.771 & .442 & -.054 \\
\hline
\end{tabular}

correlations indicate the correlation between each predictor and the dependent variable after controlling for the effect of the other variables and suggested that musicians' perceived level of group performance anxiety was positively correlated with that of solo performances. They also evidenced that the perceived impact of anxiety on the quality of performance affected the perceived anxiety level (with impairment of performance being related to higher anxiety levels). The two variables related to musical genre suggested that jazz and popular musicians were less anxious compared to classical musicians (the reference category) in solo performances.

Predictors of perceived group performance anxiety level. The three regression models computed were all statistically significant. The first regression model had $\left.R^{2}=.07, p=.019\right)$. The addition of Block 2 variables in model 2 resulted in a significant increase in $R^{2}\left(R^{2}\right.$ increase $=.331, p(F$ change $<.0001)$. The addition of musical genre in Block 3 did not reliably improve $R^{2}\left(R^{2}\right.$ increase $=.02, p(F$ change $)>.05)$. Therefore, model 2 appeared to be the most suitable for predicting group performance anxiety level. This model $(F(10,101)=6.80, p<.0001))$ had an effect size, as calculated by the multiple $R$ of $.65, R^{2}=.43$ and the adjusted $R^{2}=.37$, indicating that the model explained $37 \%$ of the variance in perceived group performance anxiety. Table 5 summarizes the individual contributions of the predictor variables.

Overall, one variable made a statistically significant contribution to the regression model, 'total perceived solo performance anxiety' (semi-partial $r=.40$ ). The semi-partial correlations, showing the correlation between each predictor and the dependent variable after controlling for the effect of the other variables suggested that musicians' perceived group performance anxiety was related positively to their perceived solo performance anxiety.

\section{The perceived timeline of anxiety in performance}

Participants were asked to rate how distressed they felt due to performance anxiety when performing solo and as part of a group on a seven-point Likert- type scale (from no distress at all to 
Table 5. Contribution of variables in hierarchical regression on perceived group performance anxiety (Block 2)

\begin{tabular}{|c|c|c|c|c|}
\hline Predictors & $\begin{array}{l}\text { Standardized } \\
\text { beta coefficient }\end{array}$ & $t$ & Sig. & $\begin{array}{l}\text { Semi-partial } \\
\text { correlation coefficient }\end{array}$ \\
\hline Female & .148 & 1.76 & .08 & .14 \\
\hline Age & .09 & .836 & .405 & .07 \\
\hline Portfolio musician & -.114 & -1.02 & .312 & -.081 \\
\hline Experience in group performance & -.14 & -1.48 & .142 & -.118 \\
\hline $\begin{array}{l}\text { Total perceived solo performance } \\
\text { anxiety }\end{array}$ & .462 & 5.04 & $<.0001$ & .399 \\
\hline $\begin{array}{l}\text { Perceived impact of performance } \\
\text { anxiety on group performance }\end{array}$ & .04 & .394 & .695 & .031 \\
\hline Total general self-esteem & .029 & .208 & .836 & .016 \\
\hline Total general life anxiety & -.174 & -1.23 & .223 & -.097 \\
\hline $\begin{array}{l}\text { Total specific performance } \\
\text { preparation efficacy }\end{array}$ & -.017 & -.014 & .889 & -.01 \\
\hline $\begin{array}{l}\text { Total specific performance } \\
\text { efficacy }\end{array}$ & .003 & .02 & .982 & .002 \\
\hline
\end{tabular}

extreme distress) at three different points in time: one hour before, immediately before and during solo and group performances.

Solo performance. Overall, participants' self-reported distress levels due to performance anxiety one hour before and during solo performance were lower $(M=3.94$, $S D=1.61$ and $M=$ $3.46, S D=1.64$ respectively $)$, compared to immediately before the performance $(M=4.61$, $S D=1.55)$.

A two-way mixed- model ANOVA was conducted with a within-participant factor of 'time to solo performance' (three levels: one hour before, immediately before, during solo performance) and a between-participant factor of musical genre (four levels: classical, popular, jazz, Scottish traditional). This showed a large main effect of 'time to solo performance' $(F(1.78,412.73)=$ $39.25, p<.0001$, partial $\left.\eta^{2}=.15\right)$, with performance anxiety levels appearing to be higher immediately before performance $(M=4.61, S D=1.54)$ compared to one hour before $(M=$ 3.93, $S D=1.61 ; p<.0001)$ and during solo performances $(M=3.23, S D=1.64 ; p<.0001)$. Statistically significant differences were also observed between one hour before and during solo performances $(p=.002)$. The main effect for musical genre reached borderline statistical significance $\left(F\left(3,2322.52, p=.05\right.\right.$, partial $\left.\eta^{2}=.03\right)$, with classical musicians experiencing higher solo performance anxiety levels compared to Scottish traditional $(p=.04)$ and jazz $(p=$ .05) musicians in each of the three time conditions. No significant differences were evidenced between other musical genres ( $p>.05$ in all cases).

The interaction between time to performance and musical genre was not significant, indicating that the performance anxiety experiences of musicians across the four musical genres followed a similar pattern. Figure 2 indicates that distress due to performance anxiety increased as the performance approached, reaching a peak immediately before performance and decreasing significantly during the actual performance.

Group performance. Overall, the self-reported distress levels due to performance anxiety one hour before and during group performance were lower $(M=2.69, S D=1.55$ and $M=2.62, S D$ $=1.48$ respectively), compared to immediately before the performance $(M=3.30, S D=1.58)$. 


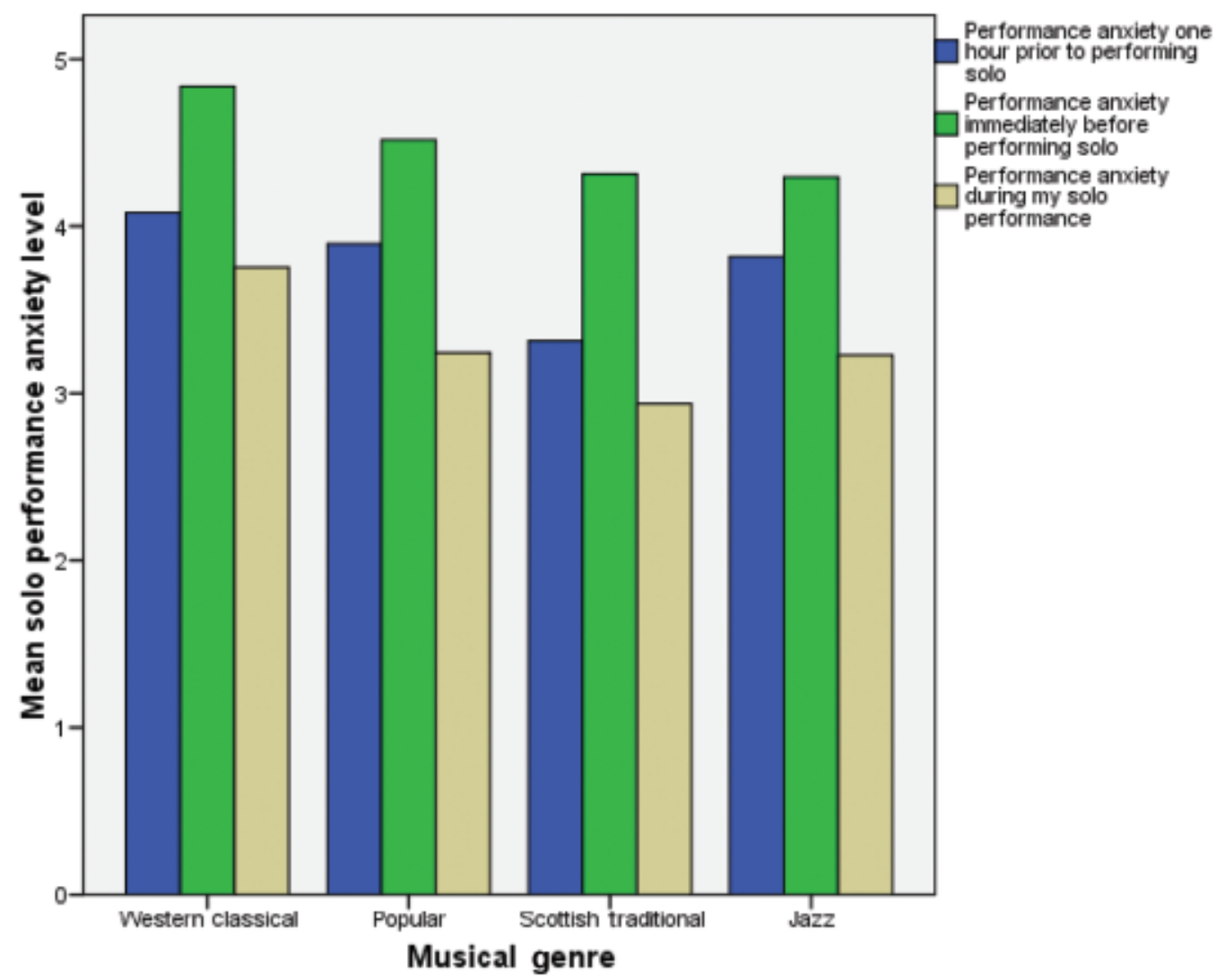

Figure 2. Solo performance anxiety levels in three time conditions by musical genre

A two-way mixed-model ANOVA was conducted with a within-participant factor of "time to group performance' (three levels: one hour before, immediately before, during group performance) and a between-participant factor of musical genre (four levels: classical, popular, jazz, Scottish traditional). This showed a moderate main effect of 'time to group performance' ( $F$ (2, $466)=15.95, p<.0001$, partial $\left.\eta^{2}=.06\right)$, with performance anxiety levels appearing to be higher immediately before performance $(M=3.3, S D=1.58)$ compared to one hour before $(M$ $=2.69, S D=1.55 ; p<.0001)$ and during group performances $(M=2.62, S D=1.48 ; p<$ .0001). No statistically significant differences were observed between one hour before and during group performances $(p>.05)$. There was no effect for musical genre $(p>.05)$, but there was a statistically significant interaction between time to group performance and musical genre $F(2,466)=4.16, p<.0001$, partial $\left.\eta^{2}=.05\right)$. Follow-up analyses indicated that whilst there were no statistically significant differences between the four musical genres in the experience of performance anxiety during group performances, and differences one hour before group performance reached borderline statistical significance $(p=.05)$, some variations were evident immediately before group performance $(p=.03)$. Popular musicians $(M=3.71, S D=1.75)$ appeared to be more anxious compared to classical $(M=3.2, S D=1.46 ; p=.04)$ and Scottish traditional musicians $(M=2.5, S D=1.46 ; p=.006)$. 
Figure 3 indicates that the experience of distress due to anxiety in group performances generally followed a similar timeline pattern to the one observed for solo performance, with distress levels increasing as the performance approached, reaching a peak immediately before performance and decreasing significantly during the actual performance. This was the case for jazz, popular and Scottish traditional musicians. A slightly different pattern was observed for classical musicians. Whilst distress levels peaked right before group performance, anxiety levels during performance appeared to be higher compared to one hour before.

\section{The perceived impact of anxiety on performance quality}

Participants were asked to rate the extent to which they felt that (a) their solo and (b) group performance suffered or improved due to performance anxiety as compared to performance without an audience on a seven-point Likert-type scale (from significantly impaired to significantly improved). Results showed that $39.3 \%$ of respondents said that their solo performance was impaired due to performance anxiety, whilst 35.2\% reported that it was improved and $25.5 \%$ that it was neither improved nor impaired. The percentage of respondents that reported

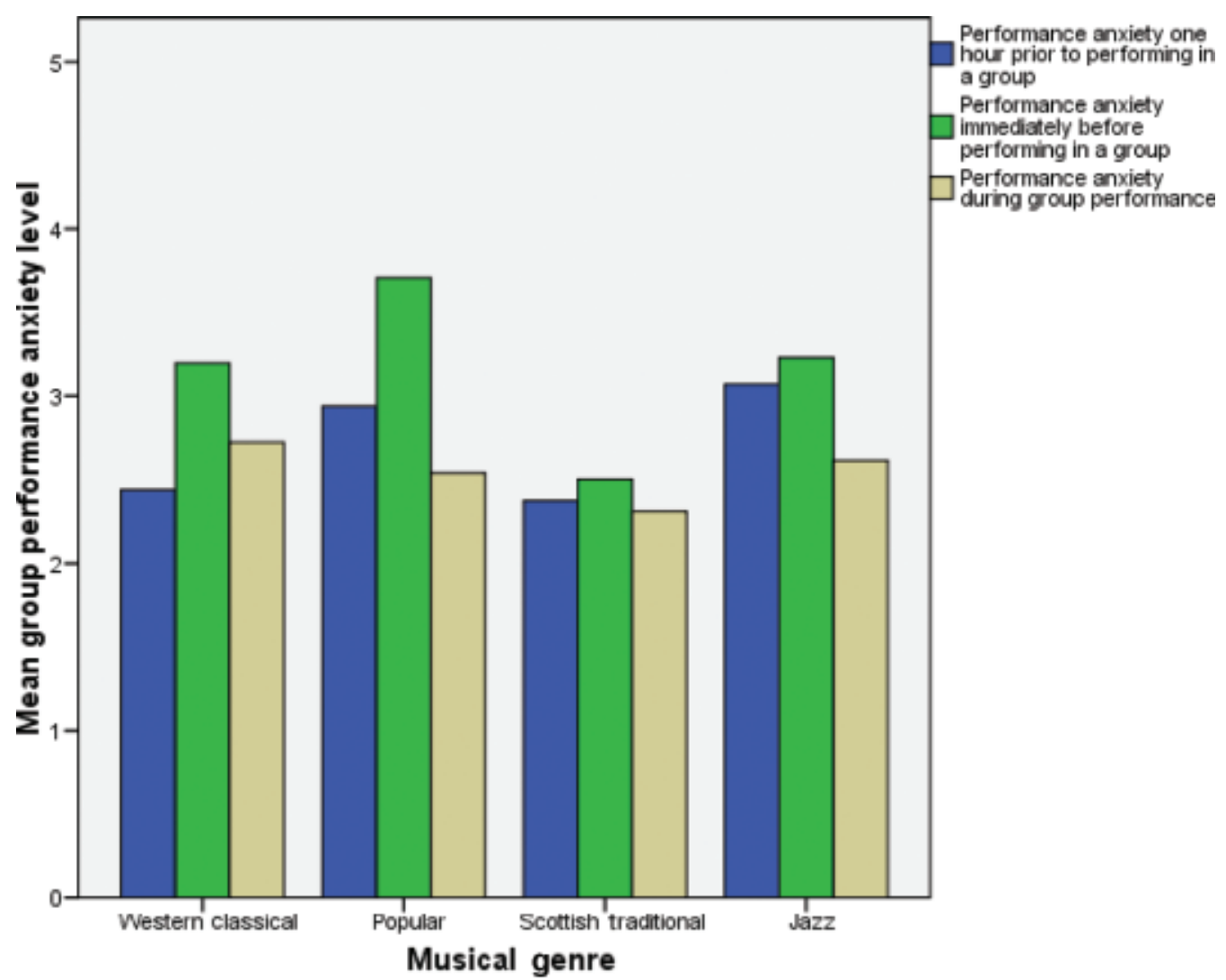

Figure 3. Group performance anxiety levels in three time conditions by musical genre 
their group performance to be impaired because of anxiety was significantly less at $22.7 \%$. Anxiety prior to group performance appeared to have more positive results compared to solo performance, as $41.4 \%$ of participants reported improvement, whereas $35.9 \%$ said that it was neither improved nor impaired.

\section{Variables predicting the perceived impact of anxiety on performance quality}

To investigate which variables could predict whether anxiety was adaptive or maladaptive to the quality of performance, two multiple hierarchical regressions were conducted, each consisting of three Blocks. The dependent variable on the first regression was 'impact of performance anxiety on solo performance' and on the second 'impact of performance anxiety on group performance' (with low values indicating impairment and high values indicating improvement).

Similarly to the regression analyses reported before, in Block 1, potential confounding variables were included (gender, age, professional status) to assess their potential impact. In Block 2 , variables related to individual and personality differences were included (experience in performance, perceived impact of performance anxiety on performance, perceived performance anxiety one hour before performance, perceived performance anxiety immediately before performance, perceived performance anxiety during performance, total general self-esteem, total general life anxiety, total specific performance preparation efficacy, total specific performance efficacy). In Block 3, musical genre was added to see if it added anything more than the preceding variables in the regression model. The same rationale for selecting predictors was repeated for the second hierarchical regression. ${ }^{6,7,8}$

Predictors of perceived impact of anxiety on solo performance. The first regression model, which consisted of potential confounding variables (age, gender, professional status) was not statistically significant $(p>.05)$, indicating that they did not affect the perceived impact of anxiety on solo performance. The second and third regression models were both statistically significant. The addition of Block 2 variables in model 2 resulted in a significant increase in $R^{2}\left(R^{2}\right.$ increase $=.761, p(F$ change $)<.0001)$. The addition of musical genre in Block 3 did not reliably improve $R^{2}\left(R^{2}\right.$ increase $=.002, p(F$ change $\left.)>.05\right)$. $)$. Model 2 was the most suitable for predicting the perceived impact of anxiety in solo performance. This model $[F(12,101)=20.73, p<.0001)$ had an effect size, as calculated by the multiple $R$ of $.86, R^{2}=.74$ and the adjusted $R^{2}=.70$, indicating that the model explained $70 \%$ of the variance in perceived impact of anxiety on solo performance. Table 6 summarizes the individual contributions of the predictor variables.

Overall, five variables made a significant contribution to the model. These were "perceived impact of anxiety on group performance' (semi-partial $r=.59$ ), 'general life anxiety' (semipartial $r=-.165$ ), 'experience in solo performance' (semi-partial $r=.163$ ), 'perceived performance anxiety immediately before solo performance' (semi-partial $r=-.157$ ) and 'perceived performance anxiety during solo performance' (semi-partial $r=-.143$ ). The semi-partial correlations suggested that musicians' perceived impact of anxiety on group performance was strongly related to how they perceived it affected their solo performance. General life anxiety was negatively correlated to the perceived impact of anxiety, suggesting that higher life anxiety levels were related to perceived impairment of performance. They also show that increased experience in solo performance was related to improvement in perceived performance quality. Perceived levels of anxiety immediately before and during solo performance were negatively correlated to the perceived impact of anxiety, suggesting that higher perceived anxiety levels were related to perceived impairment of performance. 
Table 6. Contribution of variables in hierarchical regression on perceived impact of anxiety on solo performance (Block 2)

\begin{tabular}{|c|c|c|c|c|}
\hline Predictors & $\begin{array}{l}\text { Standardized } \\
\text { beta coefficient }\end{array}$ & $t$ & Sig. & $\begin{array}{l}\text { Semi-partial } \\
\text { correlation coefficient }\end{array}$ \\
\hline Female & .060 & 1.08 & .284 & .06 \\
\hline Age & .055 & .720 & .473 & .039 \\
\hline Portfolio musician & -.089 & -1.14 & .258 & -.062 \\
\hline Experience in solo performance & .188 & 3.11 & .003 & .169 \\
\hline $\begin{array}{l}\text { Perceived impact of performance } \\
\text { anxiety on group performance }\end{array}$ & .687 & 10.85 & $<.0001$ & .59 \\
\hline $\begin{array}{l}\text { Perceived performance anxiety one } \\
\text { hour before solo performance }\end{array}$ & .116 & 1.66 & .10 & .09 \\
\hline $\begin{array}{l}\text { Perceived performance anxiety } \\
\text { immediately before solo performance }\end{array}$ & -.229 & -2.88 & .005 & -.157 \\
\hline $\begin{array}{l}\text { Perceived performance anxiety } \\
\text { during solo performance }\end{array}$ & -.183 & -2.63 & .010 & -.143 \\
\hline Total general self-esteem & -.17 & -1.76 & .08 & -.096 \\
\hline Total general life anxiety & -.292 & -2.99 & .004 & -.163 \\
\hline $\begin{array}{l}\text { Total specific performance } \\
\text { preparation efficacy }\end{array}$ & -.137 & -1.60 & .113 & -.087 \\
\hline Total specific performance efficacy & .152 & 1.47 & .146 & .080 \\
\hline
\end{tabular}

Predictors of perceived impact of anxiety on group performance. The first regression model, which consisted of potential confounding variables (age, gender, professional status) was not statistically significant $(p>.05)$, indicating that they did not affect the perceived impact of anxiety on group performance. The second and third regression models were both statistically significant. The addition of Block 2 variables in model 2 resulted in a significant increase in $R^{2}\left(R^{2}\right.$ increase $=.617, p(F$ change $)<.0001)$. The addition of musical genre in Block 3 did not reliably improve $R^{2}\left(R^{2}\right.$ increase $=.001, p(F$ change $\left.)>.05\right)$. Model 2 was the most suitable for predicting the perceived impact of anxiety in solo performance. This model $(F(12,101)=14.77, p<.0001)$ had an effect size, as calculated by the multiple $R$ of $.82, R^{2}=.67$ and the adjusted $R^{2}=.62$, indicating that the model explained $62 \%$ of the variance in perceived impact of anxiety on group performance. Table 6 summarizes the individual contributions of the predictor variables. The individual contributions of the predictor variables are summarized in Table 7 .

Overall, three variables made a significant contribution to the model. These were 'perceived impact of performance anxiety on solo performance' (semi-partial $r=.57$ ), 'experience in performance as part of a group' (semi-partial $r=.22$ ) and 'total general life anxiety' (semi-partial $r=.17$ ). The semi-partial correlations suggested that the perceived impact of anxiety on solo performance was positively correlated with the perceived impact of anxiety on group performance. They also suggested that increased performance experience was related to perceptions of performance improvement. Finally, findings indicated that, surprisingly, increased general life anxiety was related to perceptions of performance improvement as a result of anxiety.

\section{Discussion of findings}

\section{The perceived experience of anxiety in solo and group performances}

The aim of this study was to investigate perceived performance anxiety experiences in undergraduate and professional musicians and to explore whether musical genre specialization 
Table 7. Contribution of variables in hierarchical regression on perceived impact of anxiety on group performance (Block 2)

\begin{tabular}{|c|c|c|c|c|}
\hline Predictors & $\begin{array}{l}\text { Standardized } \\
\text { beta coefficient }\end{array}$ & $t$ & Sig. & $\begin{array}{l}\text { Semi-partial } \\
\text { correlation coefficient }\end{array}$ \\
\hline Female & -.076 & -1.14 & .257 & -.07 \\
\hline Age & -.152 & -1.81 & .074 & -.111 \\
\hline Portfolio musician & .044 & .497 & .620 & .03 \\
\hline $\begin{array}{l}\text { Experience in performance as part } \\
\text { of a group }\end{array}$ & .254 & 3.58 & .001 & .219 \\
\hline $\begin{array}{l}\text { Perceived impact of performance } \\
\text { anxiety on solo performance }\end{array}$ & .657 & 9.37 & $<.0001$ & .574 \\
\hline $\begin{array}{l}\text { Perceived performance anxiety one } \\
\text { hour before group performance }\end{array}$ & .070 & .782 & .436 & .048 \\
\hline $\begin{array}{l}\text { Perceived performance anxiety } \\
\text { immediately before group } \\
\text { performance }\end{array}$ & .012 & .111 & .912 & .007 \\
\hline $\begin{array}{l}\text { Perceived performance anxiety } \\
\text { during group performance }\end{array}$ & -.053 & -.628 & .532 & -.038 \\
\hline Total general self-esteem & .173 & 1.60 & .113 & .098 \\
\hline Total general life anxiety & .298 & 2.74 & .007 & .168 \\
\hline $\begin{array}{l}\text { Total specific performance } \\
\text { preparation efficacy }\end{array}$ & .044 & .462 & .646 & .028 \\
\hline Total specific performance efficacy & -.057 & -.488 & .627 & -.030 \\
\hline
\end{tabular}

(Western classical, jazz, popular, Scottish traditional) affected musicians' performance anxiety experiences, as reported on a questionnaire survey. The study addressed questions exploring the perceived intensity of performance anxiety, the perceived contributing factors, changes in perceived anxiety levels as performances approached (one hour before, immediately before and during performance) and the perceived impact of performance on the quality of performance.

Our findings suggest that solo performances tended to evoke higher levels of performance anxiety compared to group performances. This is line with literature suggesting that the more exposed a performer feels the more likely it is that they will be anxious (Wilson, 1997). Existing literature focusing on Western classical musicians has reported that the presence of peers and critics, solo performance, and small orchestras as opposed to large ones correlate with heightened performance anxiety (Brotons, 1994; Fishbein et al., 1988; Gustafson \& Rawson, 1983; Leglar, 1978). Our study suggests that this is also the case for musicians specializing in other musical genres such as popular, jazz and Scottish traditional. Our findings are in agreement with literature suggesting that and that solo performances are more anxiety inducing compared to performances as part of a group (Ryan \& Andrews, 2009) and that performing as part of a group may relieve some of the pressure of performance, indicated by a decrease in nervousness levels (Jackson \& Latané, 1981).

The level of perceived performance anxiety was affected by individual differences. Female musicians reported experiencing higher levels of anxiety, corroborating earlier research with classical student and professional musicians (e.g., Dews \& Williams, 1989; Fishbein et al., 1988; Rae \& McCambridge, 2004; Wesner et al., 1990). The effects of gender varied in relation to participants' professional experience. The difference in performance anxiety between female and male musicians was larger in the more experienced group compared to undergraduate musicians. The effects of gender and professional experience also varied with respect to musical 
genre, as indicated in Figure 1. In solo performances, classical and jazz female undergraduate musicians reported higher levels of performance anxiety. In the Scottish traditional and popular musical genres female portfolio musicians were more anxious. A similar pattern was observed in group performance, with the exception of jazz and Scottish traditional musical genres. Female jazz undergraduate and portfolio musicians reported similar anxiety levels and female undergraduate Scottish traditional musicians reported experiencing higher levels of anxiety. This interaction between gender, professional experience and musical genre could be an indication that the type of music performed and the performance context can affect how those who are more susceptible to experiencing performance anxiety (female and less experienced musicians) respond to stressful situations, as indicated by the differences observed in the interactions when comparing solo and group performances.

The variables that predicted the perceived intensity of performance anxiety experiences were explored to investigate what factors appear to correlate with higher performance anxiety. In solo performances, these included the experience of high levels of anxiety during group performances, impairment of performance quality, and increased likelihood of specializing in Western classical as opposed to jazz or popular music. In group performances, significant predictors of high levels of performance anxiety were related to experiencing high levels of anxiety in solo performances. These findings suggest that musicians who tended to be highly anxious experienced increased anxiety in both solo and group performances, and that they felt that it led to a decrease in the quality of performance, particularly when playing solo. Classical musicians in particular were more anxious in solo performances, which could relate to the fact that they are more likely to perform solo compared to musicians of other musical genres.

\section{The perceived timeline of anxiety in performance}

Reported anxiety levels increased as solo and group performances approached. These followed a pattern described in previous literature as facilitating optimal performance (e.g., Salmon et al., 1989; Wilson, 2002), as anxiety peaked right before performance and decreased significantly during the event. A similar pattern was evident across the four musical genres in solo performances. Whilst there was no difference in overall group performance anxiety levels between the four musical genres (there was no main effect for musical genre), the interaction between musical genre and time to performance indicated some differences immediately before group performances. Popular musicians appeared to experience higher levels of distress compared to their classical and Scottish traditional counterparts.

Classical musicians experienced higher levels of performance anxiety in solo performances compared to Scottish traditional and jazz musicians in the three time conditions, which implies that the classical performance context in particular may contribute to musicians feeling more nervous as performances approach, as well as during them.

\section{The perceived impact of performance anxiety on performance}

When participants were asked whether their performance was impaired or improved as a result of performance anxiety, their responses indicated that the perceived effect of anxiety differed with respect to the type of performance (solo or group). Whilst the largest percentage of respondents reported that their solo performance was impaired as a result of anxiety, most musicians felt that their group performance improved. 
The hierarchical regressions revealed variables predicting whether musicians perceived the effects of anxiety to be beneficial (adaptive performance anxiety) or detrimental (maladaptive performance anxiety) to the quality of performance. With respect to solo performances, findings suggest that the experience of high levels of group performance anxiety was a predictor of experiencing intense anxiety in solo performance too. Other predictors of maladaptive performance anxiety were a tendency to respond with heightened anxiety in various aspects of one's life (high trait anxiety), as well as perceptions of distress as a result of anxiety immediately before and during performance. Predictors of the perceived effect of anxiety in group performance included somewhat similar variables. The experience of high levels of solo performance anxiety was an important predictor of perceptions of impairment of performance. More extensive experience in playing as part of a group was related to perceptions of performance improvement. Contrary to our expectations, high trait anxiety was a predictor of performance improvement. Earlier studies have suggested a relationship between an individual's trait anxiety level and evidenced state anxiety (Cox \& Kenardy, 1993; Hamann, 1982; Kemp, 1996; Reubart, 1985; Wilson, 2002), as high trait anxiety often relates to a sensitivity towards negative evaluation and fear of failure. Our findings suggest that trait anxiety had a different effect on the quality of performance, depending on whether musicians played solo or in a group. High levels of trait anxiety tended to impair solo performances but were related to improved performance as part of a group. Performance experience appeared to counterbalance the negative effects of performance anxiety, as increased experience was related to perceptions of improvement to the quality of performance. This could be described as adaptive performance anxiety. It is possible that this happens because seasoned performers learn to control physiological arousal so that it peaks right before and decreases during performance (Salmon et al., 1989) and/or because pre-performance arousal is not perceived to pose a threat to performance, but rather as something to be expected as part of performance (Salmon \& Meyer, 1998).

It was interesting that the perceived experience of anxiety during or before group performance was not a significant predictor of perceptions of quality impairment, as was the case in solo performances. A possible explanation could be that when musicians play as part of a supportive group, their individual anxiety level does not necessarily influence the overall performance quality, which is a result of a joint activity between co-performers. Furthermore, high levels of trait anxiety were related to the perceptions of performance improvement as part of a group (adaptive group performance anxiety). This was an unexpected finding, which could indicate that when musicians play as part of a group, even if they are predisposed to being anxious as individuals, the quality of the overall performance is not affected to the same extent as solo performance, as the responsibility of the outcome is divided between co-performers.

\section{Conclusion}

The study suggests that performance anxiety is of concern for a significant majority of undergraduate and professional musicians and adds to the existing body of knowledge by exploring its presence across four musical genres. Findings suggest that musicians from the four participating musical genres (Western classical, popular, jazz, Scottish traditional) shared similar perceptions and concerns. Anxiety appeared to have negative connotations and be a problem for a number of them, although it was also reported that it can be beneficial. Solo performance appeared to generate more anxiety compared to performing as part of a group. Overall, the impact of anxiety on performance appeared to relate to its perceived severity during performance, and was mediated by musicians' performance experience and their general susceptibility to anxiety. 
As a variety of personal factors appear to influence how individuals conceptualize and respond to performance anxiety, successful strategies for coping with the demands of performance need to be person- and performance-specific, as individuals' performance anxiety thresholds can vary between different performances. For example, more specialized techniques may be appropriate for people that experience high trait anxiety as a result of other life events. Additionally, specific performance factors (type of performance, context and musical style) add to the variability of how a musician responds to the demands of a particular performance. Previous research has demonstrated differences and inconsistencies between subjective (self-report) and objective (physiological) measurements of anxiety, suggesting that there are variations in the performance anxiety thresholds of individuals (Abel \& Larkin, 1990; LeBlanc et al., 1997) that might influence how musicians perceive and respond to physiological arousal.

The musical genre in which participants specialized affected their perceived anxiety levels. Western classical musicians were generally found to report higher levels of performance anxiety compared to musicians from the other musical genres, especially in solo performances. This indicates that the specific performance context can influence musicians' perceptions and efficiency to cope with the demands of performance. The formality of the context within which classical musicians operate perhaps contributes to creating additional pressure and, subsequently, increasing anxiety levels. Further research is needed to investigate how genrespecific contexts might influence musical performance anxiety so that strategies to deal with the demands of performance can be adapted accordingly. Our findings suggest that the interaction of musical genre specialization with other key variables (such as gender, professional experience, susceptibility to general life anxiety, perceptions about its impact on the quality of performance, type of performance - solo or group) is likely to determine the extent to which musicians will experience performance anxiety and how it is going to affect the quality of performance.

In conclusion, this study has provided indications that musicians specializing in different musical genres may experience performance anxiety in quantitatively and qualitatively different ways. Further research would benefit from investigating the factors contributing to these variations in the perception of performance anxiety in musicians. Possible areas where future research could focus upon include the length of performance experience (other-than-classical musicians generally begin their engagement with music at a later age compared to Western classical performers (Gruber et al., 2004; Creech et al., 2008), the type of music performed (repertoire) and the quality of the performance context (formal or informal) across different musical genres.

\section{Notes}

1. PDF is a fixed-layout document format used for representing two-dimensional documents in a manner independent of the application software, hardware, and operating system.

2. Independent variables (predictors) on each regression were as follows: Block 1: Gender (categorical variable recoded as a dummy variable showing the effect of being female rather than male), Professional status (categorical variable recoded as a dummy variable showing the effect of being a portfolio musician as opposed to an undergraduate) and Age; Block 2: Experience in solo/group performance, Total perceived solo/group performance anxiety level, 2 Impact of performance anxiety on group/solo performance. 3 Total general self esteem, Total general life anxiety, Total specific performance preparation efficacy, Total specific performance efficacy; Block 3: Musical genre (categorical variable recoded as three dummy variables showing the effect of being a popular, jazz and Scottish traditional musician as opposed to classical). 
3. Total group performance anxiety was used as a predictor of solo performance anxiety, whilst total solo performance anxiety was included as a predictor of group performance anxiety regression.

4. Impact of solo performance anxiety was used as a predictor of solo performance anxiety, whilst impact of group performance anxiety was included as a predictor of group performance anxiety.

5. Independent variables (predictors) on each regression were as follows: Block 1: Gender (categorical variable recoded as a dummy variable showing the effect of being female rather than male), Professional status (categorical variable recoded as a dummy variable showing the effect of being a portfolio musician as opposed to an undergraduate) and Age; Block 2: Experience in solo/group performance, Total perceived solo/group performance anxiety level,2 Impact of performance anxiety on group/solo performance, 3 Total general self esteem, Total general life anxiety, Total specific performance preparation efficacy, Total specific performance efficacy; Block 3: Musical genre (categorical variable recoded as three dummy variables showing the effect of being a popular, jazz and Scottish traditional musician as opposed to classical).

6. Experience in solo performance was used as a predictor of the impact of anxiety on solo performance, whilst experience in group performance was included as a predictor of the impact of anxiety on group performance.

7. Impact of performance anxiety on solo performance was used as a predictor of the impact of performance anxiety on group performance, whilst impact of performance anxiety on group performance was included as a predictor of the impact of performance anxiety on solo performance.

8. Performance anxiety one hour before, immediately before and during solo performance was used as a predictor of the impact of performance anxiety on solo performance. Performance anxiety one hour before, immediately before and during group performance was used as a predictor of the impact of performance anxiety on group performance.

\section{References}

Abel, J. L., \& Larkin, K. T. (1990). Anticipation of performance among musicians: Physiological arousal, confidence, and state-anxiety. Psychology of Music, 18, 171-182.

Bandura, A. (1997). Self-efficacy: The exercise of control. New York: W. H. Freeman.

Barlow, D. H. (1988). Anxiety and its disorders. New York: Guildford Press.

Brotons, M. (1994). Effects of performing conditions on music performance anxiety and performance quality. Journal of Music Therapy, 31(1), 63-81.

Clark, D. M., \& Agras, W. S. (1991). The assessment and treatment of performance anxiety in musicians. American Journal of Psychiatry, 148(5), 598-605.

Cooper, C. L., \& Wills, G. I. D. (1989). Popular musicians under pressure. Psychology of Music, 17, 22-36.

Cooper, P., \& McIntyre, D. (1993). Commonality in teachers' and pupils' perceptions of effective classroom learning. British Journal of Educational Psychology, 63, 381-399.

Cox, W. J., \& Kenardy, J. (1993). Performance anxiety, social phobia and setting effects in instrumental music students. Journal of Anxiety Disorders, 7, 49-60.

Creech, A., Papageorgi, I., Duffy, C., Potter, J., Whyton, T., Morton, F., ... et al. (2008). Investigating musical performance: Commonality and diversity amongst classical and non-classical musicians. Music Education Research, 10(2), 215-234.

Dews, C. L. B., \& Williams, M. S. (1989). 'Student musicians' personality styles, stresses, and coping patterns. Psychology of Music, 17, 37-47.

Fishbein, M., Middlestadt, S. E., Ottati, V., Strauss, S., \& Ellis, A. (1988). Medical problems among ISCOM musicians: Overview of a national survey. Medical Problems of Performing Artists, 3, 1-8.

Folkman, S., \& Lazarus, R. S. (1980). An analysis of coping in a middle-aged community sample. Journal of Health and Social Behavior, 21, 219-239.

Folkman, S., Lazarus, R. S., DeLongis, A., \& Gruen, R. J. (1986). Dynamics of a stressful encounter: cognitive appraisal, coping, and encounter outcomes. Journal of Personality and Social Psychology, 50(5), 992-1003. 
Gruber, H., Degner, S., \& Lehmann, A. C. (2004). Why do some commit themselves in deliberate practice for many years - and so many do not? Understanding the development of professionalism in music. In M. Radovan \& N. Dordević (Eds.), Current issues in adult learning and motivation (pp. 222-235). Ljubljana: Slovenian Institute for Adult Education.

Gustafson, E., \& Rawson, D. (1983). Rambfeber hos strakmusiker [Stage fright in string players]. Unpublished Masters Thesis, Uppsala University, Uppsala, Sweden.

Hallam, S. (1998). Instrumental teaching: A practical guide to better teaching and learning. Oxford: Heinemann.

Hamann, D. L. (1982). An assessment of anxiety in instrumental and vocal performances. Journal of Research in Music Education, 30, 77-90.

Hargreaves, D., Welch, G. Purves, R., \& Marshall, N. (2003). Effective teaching in secondary school music: Teacher and pupil identities (Teacher identities in music education (TIME) project). ESRC End of Award Report.

Havas, K. (1995). The release from tension and anxiety in string playing. In C. Grindea (Ed.), Tensions in the performance of music (pp. 13-27). London: Kahn \& Averill.

Jackson, J. M., \& Latané, B. (1981). All alone in front of all those people: Stage fright as a function of number and type of co-performers and audience. Journal of Personality and Social Psychology, 40(1), $73-85$.

Kemp, A. E. (1996). The musical temperament: Psychology and personality of musicians. Oxford: Oxford University Press.

Kenny, D., Davis, P., \& Oates, J. (2004). Music performance anxiety and occupational stress amongst opera chorus artists and their relationship with state and trait anxiety and perfectionism. Anxiety Disorders, $18,757-777$.

Kenny, D., \& Osborne, M. S. (2006). Music performance anxiety: New insights from young musicians. Advances in Cognitive Psychology, 2(2-3), 103-112.

Kesselring, J. (2006). Music performance anxiety. In E. Altenmüller, M. Wiesendanger, \& J. Kesselring (Eds.), Music, motor control and the brain (pp. 309-318). Oxford: Oxford University Press.

Lang, P. J., Miller, G. A., \& Levin, D. (1988). Anxiety and fear. In R. J. Davidson, G. E. Schwartz, \& D. Shapiro (Eds.), Consciousness and self-regulation (pp. 123-151). New York: Plenum.

LeBlanc, A. (1994). A theory of music performance anxiety. The Quarterly Journal of Music Teaching and Learning, 5, 60-68.

LeBlanc, A., Jin, Y. C., Obert, M., \& Siivola, C. (1997). Effect of audience on music performance anxiety. Journal of Research in Music Education, 45(3), 480-496.

Leglar, M. P. (1978). Measurement of indicators of anxiety levels under varying conditions of musical performance. Dissertations Abstracts International, 39, 5201A-5202A.

Lehrer, P. M. (1987). A review of the approaches to the management of tension and stage fright in music performance. Journal of Research in Music Education, 35(3), 143-153.

Levitt, E. E. (1968). The psychology of anxiety. London: Staples Press.

Marchant-Haycox, S. E., \& Wilson, G. D. (1992). Personality and stress in performing artists. Personality and Individual Differences, 13, 1061-1068.

Martens, R., Burton, D., Vealey, R., Bump, L., \& Smith, D. (1990). The development of the competitive state anxiety inventory-2 (CSAI-2). In R. Martens, R. S. Vealey, \& D. Burton (Eds.), Competitive anxiety in sport (pp. 117-190). Champaign, IL: Human Kinetics.

Miller, S. R., \& Chesky, K. (2004). The multidimensional anxiety theory: An assessment of and relationships between intensity and direction of cognitive anxiety, somatic anxiety, and self-confidence over multiple performance requirements among college music majors. Medical Problems of Performing Artists, 19(1), 12-20.

Osborne, M. S., \& Franklin, J. (2002). Cognitive processes in music performance anxiety. Australian Journal of Psychology, 54(2), 86-93.

Osborne, M. S., \& Kenny, D. (2008). The role of sensitizing experiences in music performance anxiety in adolescent musicians. Psychology of Music, 36(4), 447-462. 
Pajares, F. (1996). Self-efficacy beliefs and mathematical problem-solving of gifted students. Contemporary Educational Psychology, 21, 325-344.

Papageorgi, I. (2006). Understanding performance anxiety in the adolescent musician. Unpublished PhD thesis. Institute of Education, University of London.

Papageorgi, I. (2007). The influence of the wider context of learning, gender, age and individual differences on adolescent musicians' performance anxiety. In A. Williamon \& D. Coimbra (Eds.), Proceedings of the International Symposium on Performance Science (pp. 219-224). Utrecht, The Netherlands: European Association of Conservatoires (AEC).

Papageorgi, I., Hallam, S., \& Welch, F. G. (2007). A conceptual framework for understanding musical performance anxiety. Research Studies in Music Education, 28(1), 83-107.

Papageorgi, I., \& Kopiez, R. (in press). Psychological and physiological aspects of learning to perform. In G. McPherson \& G. Welch (Eds.), The Oxford handbook of music education. Oxford: Oxford University Press.

Rae, G., \& McCambridge, K. (2004). Correlates of performance anxiety in practical music exams. Psychology of Music, 32(4), 432-439.

Rapee, R. M., \& Heimberg, R. G. (1997). A cognitive-behavioral model of anxiety in social phobia. Behavior Research and Therapy, 35(8), 741-756.

Reubart, D. (1985). Anxiety and musical performance: On playing the piano from memory. New York: Da Capo Press.

Rosenberg, M. (1989). Society and the adolescent self-image (rev. ed.). Middletown, CT: Wesleyan University Press.

Ryan, C. (2004). Gender differences in children's experience of musical performance anxiety. Psychology of Music, 32(1), 89-103.

Ryan, C., \& Andrews, N. (2009). An investigation into the choral singer's experience of music performance anxiety. Journal of Research in Music Education, 57(2), 108-126.

Salmon, G., \& Meyer, R. G. (1998). Notes from the green room: Coping with stress and anxiety in musical performance. San Francisco, CA: Jossey-Bass Publishers.

Salmon, P. G. (1990). A psychological perspective on musical performance anxiety: A review of the literature. Medical Problems of Performing Artists, 5(1), 2-11.

Salmon, P., Schrodt, R., \& Wright, J. (1989). A temporal gradient of anxiety in a stressful performance context. Medical Problems of Performing Artists, 4(2), 77-80.

Schulz, W. (1981). Analysis of a Symphony Orchestra. In M. Piperek (Ed.), Stress and music: Medical, psychological, sociological, and legal strain factors in a symphony orchestra musicians' profession (pp. 35-56). Vienna: Wilhelm Braumuller.

Schwarzer, R., \& Jerusalem, M. (1992). Advances in anxiety theory: A cognitive process approach. In K. A. Hagtvet \& B. T. Johnsen (Eds.), Advances in test anxiety research, Vol. 7 (pp. 2-17). Lisse, the Netherlands: Swets and Zeitlinger.

Sherer, M., Maddux, J. E., Mercandante, B. Prentice-Dunn, S., Jacobs, B., \& Rogers, R. W. (1982). The selfefficacy scale: Construction and validation, Psychological Reports 51, 663-671.

Spencer, R. L. (1969). A study of the relationship of situational anxiety to vocal solo performances of college freshmen voice students. Dissertation Abstracts International, 1970(31), 238A (University Microfilms No. 70-9158).

Spielberger, C. D. (1983). Manual for the state-trait anxiety inventory (Form Y). Palo Alto, CA: Consulting Psychologist Press.

Steptoe, A. (1989). Stress, coping and stage fright in professional musicians. Psychology of Music, 17, $3-11$.

Steptoe, A. (2001). Negative emotions in music making: The problem of performance anxiety. In P. N. Juslin \& J. A. Sloboda (Eds.), Music and emotion: Theory and research (pp. 291-307). Oxford: Oxford University Press.

Steptoe, A., \& Fidler, H. (1987). Stage fright in orchestral musicians: A study of cognitive and behavioural strategies in performance anxiety. British Journal of Psychology, 78, 241-249. 
Turner, S. M., \& Beidel, D. C. (1989). Social phobia: Clinical syndrome, diagnosis and comorbidity. Clinical Psychology Review, 9, 3-18.

Welch, G., Hallam, S., Lamont, A., Swanwick, K., Green, L., Hennessy, S., Cox, G., O’Neill, S., \& Farrell, G. (2004). Mapping music education research in the UK. Psychology of Music, 32(3), 239-290.

Wesner, R. B., Noyes, R., \& Davis, T. L. (1990). The occurrence of performance anxiety among musicians. Journal of Affective Disorders, 18, 177-185.

Williamon, A., \& Thompson, S. (2006). Awareness and incidence of health problems among conservatoire students. Psychology of Music, 34(4), 411-430.

Wills, G., \& Cooper, C. L. (1988). Pressure sensitive: Popular musicians under stress. London: Sage.

Wilson, G. D. (1973). Abnormalities in motivation. In H. J. Eysenck (Ed.), Handbook of abnormal psychology (pp. 362-389). London: Pitman Medical.

Wilson, G. D. (1997). Performance anxiety, in D. J. Hargreaves \& A. C. North (Eds.), The social psychology of music (pp. 229-245). Oxford: Oxford University Press.

Wilson, G. D. (2002). Psychology for performing artists (2nd ed.). London: Whurr.

Wolfe, M. L. (1990). Coping with musical performance anxiety: Problem-focused and emotion-focused strategies. Medical Problems of Performing Artists, 5(1), 33-36.

Yerkes, R. M., \& Dodson, J. D. (1908). The relation of strengths of stimulus to rapidity of habit formation. Journal of Comparative Neurological Psychology, 18, 459-482.

Yoshie, M., Kudo, K., Murakoshi, T., \& Ohtsuki, T. (2009). Music performance anxiety in skilled pianists: Effects of social-evaluative performance situation on subjective, autonomic, and electromyographic reactions. Experimental Brain Research, 199(2), 117-126.

\section{Author biographies}

Dr loulia Papageorgi is a Lecturer in Psychology and Human Development and a Coordinating Research Officer in the Faculty of Children and Learning at the Institute of Education, University of London. She is also an Associate Lecturer at the Open University. She has degrees in both Music and Psychology from the University of Leeds and the Open University, respectively. She has a Master's degree in Music Education and a Doctorate in Psychology in Education from the Institute of Education, University of London. Her research interests focus on the development of expertise, the psychology of performance and performance anxiety. She has worked in research teams for various funded research projects, and has widely presented her work at international conferences and seminars. She has published papers in international peerreviewed journals and conference proceedings, and has authored a number of invited book chapters. Ioulia is a Chartered Psychologist (CPsychol), an Associate Fellow of the British Psychological Society (AFBPsS) and a Fellow of the Higher Education Academy (FHEA).

Dr Andrea Creech has extensive experience as a professional musician, music teacher and researcher. She has held principal positions in orchestras in the UK and Canada and subsequently was founder and director of a Community Music School in the Republic of Ireland. Her $\mathrm{PhD}$ research was concerned with the impact on learning outcomes of interpersonal interaction amongst violin students, their parents and teachers. Andrea has worked on research teams for a number of funded projects including Investigating Music Performance (ESRC/TLRP), evaluation of CPD for Music Leaders (Youth Music), Evaluation of Behaviour Improvement Programme (DfES), Evaluation of Voices Foundation Primer (DfES), National Survey of Music Services 2005 (DfES), Evaluation of Skill Force in Kent Schools (DfES), investigating the PhD Student Experience (IOE) and a collaborative project on motivation, aspirations and self-perceptions in the Conservatoire with an international research group. Her special research interests are musical development across the lifespan and the impact of interpersonal relationships on 
learning and teaching outcomes. Andrea has presented her work at international conferences and published widely.

Professor Graham Welch holds the Institute of Education, University of London Established Chair of Music Education and is Head of the Institute's Department of Early Childhood and Primary Education. He is President of the International Society for Music Education (ISME), elected Chair of the internationally based Society for Education, Music and Psychology Research (SEMPRE) and past Co-Chair of the Research Commission of ISME. Current Visiting Professorships include the Universities of Queensland (Australia), Limerick (Eire) and Roehampton (UK). He is also a member of the UK Arts and Humanities Research Council's (AHRC) Review College for Music and has been a specialist consultant for Government departments and agencies in the UK, Italy, Sweden, USA, Ukraine, UAE, South Africa and Argentina on aspects of music, education and teacher education. Publications number over two hundred and seventy and embrace musical development and music education, teacher education, the psychology of music, singing and voice science, as well as music in special education and disability. Publications are primarily in English, but also appear in Spanish, Portuguese, Italian, Swedish, Greek, Japanese and Chinese. 